\title{
Pengaruh Disiplin Kerja, Pengalaman Kerja dan Budaya Organisasi terhadap Kinerja Karyawan pada PT. Kumala Indonesia Shipyard
}

\author{
Suci Amalia \\ Universitas Putera Batam \\ Pb160610019@upbatam.ac.id
}

\section{Mauli Siagian \\ Universitas Putera Batam \\ Mauli@puterabatam.ac.id}

\begin{abstract}
Abstrak Human resources are main resources in an organization that functions as main organization and the activities of the organization as well as one of the main spearheads for each organization's operations. And besides increasing human resources also required aspects of the company that are needed to provide knowledge well to carry out direction of the organization. Purpose of this study was to study the partial and simultaneous interaction of work discipline variables, work experience, and organizational culture on employee performance at PT Kumala Indonesia Shipyard. This quantitative study used sampling technique of 107 participants. Data collection was carried out by questionnaire interviews with all respondents using a Likert scale as a measurement scale and SPSS Version 22 as a data processing application. As a result of the T-Test, the partial variables of work coordination, work experience, and organizational culture have a positive and significant influence on the performance of the employees of PT Kumala Indonesia Shipyard. And results of the F Test states that simultaneous work variables and positive and significant work experience on employee performance, work experience and simultaneous organizational culture have a positive and significant effect on employee performance.
\end{abstract}

Kata Kunci Employee Performance, Organizational Culture, Work Discipline, Work Experience.

\section{PENDAHULUAN}

Setiap organisasi pemerintah atau perusahaan diminta agar bisa meningkatkan sumber daya manusia juga bagaimana sumber daya itu bisa dikembangkan dengan sangat bagus. Dan disamping peningkatan sumber daya manusia juga terdapat aspek pada karyawan yang diperlukan mampu memiliki pengetahuan dengan baik untuk dapat melaksanakan arahan dari organisasi. Disiplin kerja yang bagus merupakan sikap dan kepribadian serta tindakan yang sinkron pada aturan dari organisasi yang bersangkutan secara tertulis dan tidak tertulis. Disiplin kerja juga sebagai aspek utama yang menjadikan kesadaran terhadap aturan perusahaan pernyataan ini didukung oleh (Acel \& Abrian, 2019:63). Menurut (Ratnasih, 2019:294) pengalaman kerja yakni sistem dari terciptanya pemahaman maupun keahlian mengenai prosedur dari pekerjaan karena keterlibatan karyawan tersebut dalam menyelesaikan tugasnya. Budaya organisasi juga berpengaruh dalam kinerja seorang karyawan dimana menurut (Prahasti \& Wahyono, 2018:544) 
bahwa budaya yang erat bisa menciptakan dampak yang cukup mempengaruhi individu serta kinerja, maupun pada suatu golongan yang berdampingan pengaruh itu bisa sangat kuat dibanding penyebab lain misalnya sistem organisasi, instrument analisis keuangan, kepemimpinan serta yang lainnya. Pada dasarnya kinerja itu hasil pekerjaan yang diselesaikan oleh karyawan yang bersumber dari pada aturan pekerjaan pernyataan ini didukung oleh (Prahasti \& Wahyono, 2018:544). Dalam mencapai kinerja yang baik setiap karyawan perlu memahami standart operasional pekerjaan dengan mengetahui poin-poin apa saja yang bisa dikerjakan maupun yang tidak bisa dikerjakan dalam setiap pekerjaan dan bertanggung jawab untuk menuntaskan pekerjaan tersebut pada target yang sudah dibuat pada sebuah organisasi. Hal ini juga dapat menentukan arah kebijakan pengambilan keputusandan membuat peningkatan sunber daya manusia secara maksimal dalam mencapai tujuan perusahaan. PT Kumala Indonesia Shipyard ialah perusahaan yang bergerak pada bidang industri galangan kapal yang mana merupakan salah satu perusahaan yang menghasilkan kapal tank, tongkang dan kapal kargo yang berlokasi di JL. Brigadir Jendral Katamso Km 6, Tanjung Uncang Kec. Batu Aji Kota Batam Kepulauan Riau. Kedisiplinan karyawan yang masih kurang dapat dilihat dari karyawan yang kerap terlambat masuk kerja , karyawan yang berlama-lama izin ke toilet sehingga menganggu jam kerja yang mengakibatkan berkurangnya jam kerja untuk menyelesaikan pekerjaannya yang sudah diatur oleh perusahaan. Perolehan target yang tidak sesuai bisa dilihat dari menurunnya tingkat kehadiran karyawan pada perusahaan. Pada tabel dibawah, persentase absensi sebagai berikut:

Tabel 1.1 Absensi Karyawan PT Kumala Indonesia Shipyard Januari s/d Juni

\begin{tabular}{|c|c|c|c|c|c|}
\hline No & Bulan (2020) & $\begin{array}{c}\text { Jumlah } \\
\text { Karyawan }\end{array}$ & $\begin{array}{c}\text { Hari } \\
\text { Kerja }\end{array}$ & $\begin{array}{c}\text { Persentase } \\
\text { Kehadiran }\end{array}$ & $\begin{array}{c}\text { Persentase } \\
\text { Absen }\end{array}$ \\
\hline 1 & Januari & 116 & 22 & $88 \%$ & $12 \%$ \\
\hline 2 & Februari & 102 & 20 & $94 \%$ & $6 \%$ \\
\hline 3 & Maret & 103 & 21 & $86 \%$ & $14 \%$ \\
\hline 4 & April & 89 & 21 & $90 \%$ & $10 \%$ \\
\hline 5 & Mei & 88 & 17 & $88 \%$ & $12 \%$ \\
\hline 6 & Juni & 107 & 19 & $87 \%$ & $13 \%$ \\
\hline
\end{tabular}

Sumber: PT Kumala Indonesia Shipyard 2020

\section{TINJAUAN PUSTAKA}

\section{Disiplin Kerja}

Disiplin Kerja Disiplin kerja diartikan sebagai salah satu bentuk dari kinerja representatif itu yang memenuhi elemen profesionalisme sebagai para karyawan. (Candra, Dharma, \& Sherly, 2020:367). Menurut (Prasetyo \& Marlina, 2019:24) ada beberapa macam dari disiplin kerja, yakni : Disiplin preventif dan disiplin korektif. Menurut pandangan (Rahmi, 2019:41) indikator disiplin kerja ialah tujuan kemampuan, tingkat kewaspadaan karyawaan, ketaatan pada standar kerja, ketaatan pada peraturan kerja, dan etika kerja.

\section{Pengalaman Kerja}

Menurut (Rulianti, 2019:133) pengalaman kerja ialah pemahaman serta penguasaan karyawan yang dilihat dari lama waktu dia bekerja, tahap pemahaman serta penguasaan yang dimiliki karyawan. Faktor yang bisa mempengaruhi pengalaman kerja tersebut ialah sebagai berikut (Rulianti, 2019:133) : Keramah tamahan dalam meghadapi pimpinan dan kelengkapan pengalaman kerja Adapun indikator yang menentukan karyawan itu memiliki pengalaman maupun tidak disuatu pekerjaan yakni (Rulianti, 2019:133) : Lama waktu maupun masa kerja,tingkat pemahaman atau keterampilan yang telah dimiliki,penguasaan pada pekerjaan maupun peralatan, jenis pekerjaan. 


\section{Budaya Organisasi}

Budaya organisasi itu merujuk pada sistem makna keseluruhan yang telah diyakini oleh seluruh karyawan yang membedakan organisasi itu dengan organisasi lainnya dan mencerminkan seperangkat karakteristik dari budaya organisasi pernyataan ini didukung oleh (Siagian, 2017:28). Menurut (Muis et al., 2018:13) ada 3 macam dari budaya organisasi yakni : Budaya konstruktif, Budaya pasif-defensif serta Budaya agresif defensif. Menurut (Darmasaputra \& Sudibya, 2019:5852) indikator mengukur budaya organisasi yaitu : tujuan perusahaan, konsesus, keunggulan, kesatuan, prestasi, keakraban dan integrasi.

\section{Kinerja Karyawan}

Menurut (Prasetyo \& Marlina, 2019:24) menyatakan bahwa kinerja yakni sekumpulan proses yang menggambarkan sejauh mana hasil yang telah diselesaikan oleh karyawan yang melakukan kegiatan serta tanggung jawabnya baik dengan keberhasilan ataupun dengan kekurangan yang ada. Dan perolehan dari satu proses yang mengacu serta dapat dinilai selama rentang waktu tertentu berlandaskan ketetapan maupun kesepakatan yang sudah diatur terlebih dahulu. Menurut (Sofian \& Julkarnain, 2019:145) ada beberapa faktor yang dapat mempengaruhi kinerja yakni : Kualitas pekerjaan, Kuantitas pekerjaan, Pengetahuan pekerjaan, Kerjasama tim, Kreativitas, Inovasi dan Inisiatif. Indikator kinerja karyawan menurut (Rulianti, 2019:134) antara lain : Kualitas, Kuantitas, Pelaksana tugas, dan Tanggung jawab.

\section{METODOLOGI PENELITIAN}

Metode pada penelitian ini ialah kuantitatif, yang dipakai pada populasi maupun sampel tertentu agar dapat menghasilkan data yang bersifat terstruktur sehingga peneliti dapat mengubah data menjadi angka. Populasi di penelitian ini ialah semua karyawan pada PT Kumala Indonesia Shipyard dengan total karyawan yang ada sebanyak 107 orang. Sampel yang dipakai pada penelitian ini ialah semua karyawan PT Kumala Indonesia Shipyard, hal tersebut dikarenakan jumlahnya yang relatif kecil untuk mendapatkan tingkat kesalahan yang lebih kecil teknik sampling yang akan dipakai pada penelitian ini memakai teknik non probability sampling dengan sampel jenuh. Teknik pengumpulan data yang dipakai didalam penelitian dengan memakai sumber data primer. Alat yang dipakai pada pengumpulan data dalam penelitian ini menggunakan metode kuesioner, metode ini berguna untuk menggumpulkan jawaban dari responden baik berupa pernyataan atau pertanyaan tertutup maupun terbuka, dan disajikan pada responden secara langsung ataupun internet.

\section{HASIL DAN PEMBAHASAN \\ Profil Responden}

Profil responden maupun karakteristik data responden di penelitian ini yaitu: jenis kelamin, usia, status perkawinan, pendidikan terakhir, dan lama bekerja. Karakter ini bertujuan untuk menggambarkan latar belakang para responden yang telah peneliti tetapkan sebagai sampel di penelitian ini. Dalam pengumpulan data di penelitian ini yaitu peneliti langsung menyebarkan kuesioner kepada karyawan yang bekerja di PT Kumala Indonesia Shipyard.

Tabel 4.1 Karakteristik Responden Berdasarkan Jenis Kelamin

\begin{tabular}{|l|l|l|l|}
\hline No & Kriteria & Frekuensi & Persentase(\%) \\
\hline
\end{tabular}




\begin{tabular}{|c|c|c|c|}
\hline 1 & Laki-laki & 101 & $94.4 \%$ \\
\hline 2 & Perempuan & 6 & $5.6 \%$ \\
\hline & Total & 107 & $100 \%$ \\
\hline
\end{tabular}

Sumber: Pengolahan Data SPSS 22, 2020

Tabel 4.2 Karakteristik Responden Berdasarkan Tingkat Usia

\begin{tabular}{|c|c|c|c|}
\hline No & Kriteria & Frekuensi & Persentase(\%) \\
\hline 1 & 18-25 Tahun & 20 & $18.7 \%$ \\
\hline 2 & 26-35 Tahun & 39 & $36.4 \%$ \\
\hline 3 & 36-45 Tahun & 48 & $44.9 \%$ \\
\hline & Total & 107 & $100 \%$ \\
\hline
\end{tabular}

Sumber: Pengolahan Data SPSS 22, 2020

Tabel 4.3 Karakteristik Responden Berdasarkan Status Perkawinan

\begin{tabular}{|c|c|c|c|}
\hline No & Kriteria & Frekuensi & Persentase(\%) \\
\hline 1 & Belum Kawin & 21 & $19.6 \%$ \\
\hline 2 & Kawin & 86 & $80.4 \%$ \\
\hline & Total & 107 & $100 \%$ \\
\hline
\end{tabular}

Sumber: Pengolahan Data SPSS 22, 2020

Tabel 4.4 Karakteristik Responden Berdasarkan Pendidikan Terakhir

\begin{tabular}{|c|c|c|c|}
\hline No & Kriteria & Frekuensi & Persentase(\%) \\
\hline 1 & SMA/SMK & 88 & $82.2 \%$ \\
\hline 2 & Diploma & 7 & $6.5 \%$ \\
\hline 3 & Sarjana (S1) & 12 & $11.2 \%$ \\
\hline & Total & 107 & $100 \%$ \\
\hline
\end{tabular}

Sumber: Pengolahan Data SPSS 22, 2020

Tabel 4.5 Karakteristik Responden Berdasarkan Lama Bekerja

\begin{tabular}{|c|c|c|c|}
\hline No & Kriteria & Frekuensi & Persentase(\%) \\
\hline 1 & $<1$ Tahun & 7 & $6.5 \%$ \\
\hline 2 & $1-2$ Tahun & 60 & $56.1 \%$ \\
\hline 3 & $3-5$ Tahun & 8 & $7.5 \%$ \\
\hline 4 & $>5$ Tahun & 14 & $13.1 \%$ \\
\hline 5 & Karyawan Tetap & 18 & $16.8 \%$ \\
\hline & Total & 107 & $100 \%$ \\
\hline
\end{tabular}

Sumber: Pengolahan Data SPSS 22, 2020

Tabel 4.6 Karakteristik Responden Berdasarkan Pendapatan Perbulan

\begin{tabular}{|c|c|c|c|}
\hline No & Kriteria & Frekuensi & Persentase(\%) \\
\hline 1 & 3 Juta - 4 Juta & 22 & $20.6 \%$ \\
\hline 2 & 4 Juta - 5 Juta & 53 & $49.5 \%$ \\
\hline 3 & $>$ 5 Juta & 32 & $29.9 \%$ \\
\hline & Total & 107 & $100 \%$ \\
\hline
\end{tabular}

Sumber: Pengolahan Data SPSS 22, 2020

\section{Analisis Deskriptif}


Analisis deskriptif pada penelitian ini digunakan berdasarkan jawaban responden dari hasil kuesioner yang telah didistribusikan kepada karyawan Pt Kumala Indonesia Shipyard dalam bentuk tabulasi data. Berdasarkan rentang skala yang telah diperoleh, kategori deskripsi hasil berdasarkan jawaban responden tertera dibawah ini :

Tabel 4.7 Kategori Rentang Skala

\begin{tabular}{|c|c|c|}
\hline No & Rentang Skala & Kategori \\
\hline 1 & $107-192,6$ & Sangat Tidak Setuju \\
\hline 2 & $192,7-278,3$ & Tidak Setuju \\
\hline 3 & $278,4-364$ & Cukup Setuju \\
\hline 4 & $365-450,6$ & Setuju \\
\hline 5 & $450,7-536,3$ & Sangat Setuju \\
\hline
\end{tabular}

Sumber: Peneliti 2020

\section{Hasil Uji Validitas}

Tabel 4.8 Hasil Uji Validitas Disiplin Kerja $\left(\mathrm{X}_{1}\right)$

\begin{tabular}{|c|c|c|c|c|}
\hline Variabel & Pernyataan & r hitung & r tabel & Keterangan \\
\hline \multirow{5}{*}{ Disiplin kerja (X1) } & $\mathrm{X} 1.1$ & 0,533 & & \\
\cline { 2 - 3 } & $\mathrm{X} 1.2$ & 0,558 & & \\
\cline { 2 - 3 } & $\mathrm{X} 1.3$ & 0,639 & & \\
\cline { 2 - 3 } & $\mathrm{X} 1.4$ & 0,573 & & \\
\cline { 2 - 3 } & $\mathrm{X} 1.5$ & 0,695 & \multirow{4}{*}{0,1900} & \multirow{3}{*}{ Valid } \\
\cline { 2 - 3 } & $\mathrm{X} 1.6$ & 0,406 & \\
\cline { 2 - 3 } & $\mathrm{X} 1.7$ & 0,634 & & \\
\cline { 2 - 3 } & $\mathrm{X} 1.8$ & 0,438 & & \\
\cline { 2 - 3 } & $\mathrm{X} 1.9$ & 0,366 & & \\
\cline { 2 - 3 } & $\mathrm{X} 1.10$ & 0,317 & & \\
\hline
\end{tabular}

Sumber: Pengolahan Data SPSS 22, 2020

Dari tabel diatas, dapat dilihat bahwa dalam variabel X1 dikatakan valid. Semua hasil pernyataan menunjukkan nilai $r_{\text {hitung }}>r_{\text {tabel }}$. Dengan demikian seluruh pernyataanpernyataan yang terdapat pada variabel disiplin kerja X1 dinyatakan valid atau sah dan dapat digunakan pada pengujian selanjutnya.

Tabel 4.9 Hasil Uji Validitas Pengalaman Kerja $\left(\mathrm{X}_{2}\right)$

\begin{tabular}{|c|c|c|c|c|}
\hline Variabel & Pernyataan & r hitung & $r$ tabel & Keterangan \\
\hline \multirow{8}{*}{ Pengalaman kerja (X2) } & $\mathrm{X} 2.1$ & 0,394 & \multirow{8}{*}{0,1900} & \multirow{8}{*}{ Valid } \\
\hline & $\mathrm{X} 2.2$ & 0,756 & & \\
\hline & $\mathrm{X} 2.3$ & 0,500 & & \\
\hline & $\mathrm{X} 2.4$ & 0,505 & & \\
\hline & $\mathrm{X} 2.5$ & 0,521 & & \\
\hline & $\mathrm{X} 2.6$ & 0,751 & & \\
\hline & $\mathrm{X} 2.7$ & 0,756 & & \\
\hline & $\mathrm{X} 2.8$ & 0,524 & & \\
\hline
\end{tabular}

Sumber: Pengolahan Data SPSS 22, 2020

Dari tabel 4.9 diatas, dapat dilihat bahwa dalam variabel X2 dikatakan valid. Semua pada hasil pernyataan menunjukkan nilai $r_{\text {hitung }}>r_{\text {tabel }}$. Dengan demikian seluruh pernyataan- 
pernyataan yang terdapat pada variabel disiplin kerja X2 dinyatakan valid atau sah dan dapat digunakan pada pengujian selanjutnya.

Tabel 4.10 Hasil Uji Validitas Budaya Organisasi $\left(\mathrm{X}_{3}\right)$

\begin{tabular}{|c|c|c|c|c|}
\hline Variabel & Pernyataan & r hitung & r tabel & Keterangan \\
\hline \multirow{4}{*}{ Budaya Organisasi (X3) } & X3.1 & 0,500 & & \\
\cline { 2 - 3 } & $\mathrm{X} 3.2$ & 0,609 & & \\
\cline { 2 - 3 } & $\mathrm{X} 3.3$ & 0,651 & \multirow{4}{*}{0,1900} & \multirow{3}{*}{ Valid } \\
\cline { 2 - 3 } & $\mathrm{X} 3.4$ & 0,669 & & \\
\cline { 2 - 3 } & $\mathrm{X} 3.5$ & 0,680 & & \\
\cline { 2 - 3 } & $\mathrm{X} 3.6$ & 0,574 & & \\
\hline & $\mathrm{X} 3.7$ & 0,651 & & \\
\hline
\end{tabular}

Sumber: Pengolahan Data SPSS 22, 2020

Dari tabel 4.10 tersebut, bisa dilihat bahwa dalam variabel X3 dikatakan valid. Dan semua hasil pernyataan menunjukkan nilai $r_{h i t u n g}>r_{\text {tabel. }}$. Dengan demikian seluruh pernyataanpernyataan yang terdapat pada variabel disiplin kerja X3 dinyatakan valid atau sah dan dapat digunakan pada pengujian selanjutnya.

Tabel 4.11 Hasil Uji Validitas Kinerja Karyawan (Y)

\begin{tabular}{|c|c|c|c|c|}
\hline Variabel & Pernyataan & r hitung & $r$ tabel & Keterangan \\
\hline \multirow{8}{*}{ Kinerja karyawan (Y) } & $\mathrm{Y} 1$ & 0,645 & \multirow{8}{*}{0,1900} & \multirow{8}{*}{ Valid } \\
\hline & $\mathrm{Y} 2$ & 0,699 & & \\
\hline & Y3 & 0,663 & & \\
\hline & Y4 & 0,661 & & \\
\hline & Y5 & 0,632 & & \\
\hline & Y6 & 0,326 & & \\
\hline & $\mathrm{Y7}$ & 0,586 & & \\
\hline & Y8 & 0,569 & & \\
\hline
\end{tabular}

Sumber: Pengolahan Data SPSS 22, 2020

Dari tabel 4.11 diatas, bisa dilihat bahwa dalam variabel Y dikatakan valid. Semua hasil pernyataan menunjukkan nilai $r_{\text {hitung }}>r_{\text {tabel }}$. Dengan demikian seluruh pernyataanpernyataan yang terdapat pada variabel disiplin kerja Y dinyatakan valid atau sah pada penelitian ini dan dapat diterima.

Hasil Uji Reliabilitas

Tabel 4.12 Uji Reliabilitas

\begin{tabular}{|c|c|c|c|}
\hline Variabel & $\begin{array}{c}\text { Alpha } \\
\text { Cronbach }\end{array}$ & $\begin{array}{c}\text { Koefisien } \\
\text { Alpha }\end{array}$ & \multirow{2}{*}{ Status } \\
\hline Disiplin Kerja & 0,690 & 0,6 & \multirow{2}{*}{ Reliabel } \\
\hline Pengalaman Kerja & 0,741 & 0,6 & \\
\hline Budaya Organisasi & 0,730 & 0,6 & \\
\hline Kinerja Karyawan & 0,741 & 0,6 & \\
\hline
\end{tabular}

Sumber : Hasil Pengolahan SPSS 22, diolah 2020

Berdasarkan hasil uji realibilitas pada tabel 4.12 bisa dilihat bahwa seluruh variabel pada penelitian ini mempunyai nilai Alpha Cronbach $>0,60$. Hal itu menunjukkan bahwa semua variabel yang dipakai pada penelitian ini dinyatakan reliabel. 


\section{Hasil Uji Normalitas}

Uji normalitas ini guna mengetahui apakah data yang dikumpulkan berdistribusi normal ataupun tidak. Pendekatan yang dipakai pada uji normalitas ini yakni evaluasi grafik normalitas. Hasil uji normalitas penelitian ini bisa dilihat pada gambar dibawah ini :

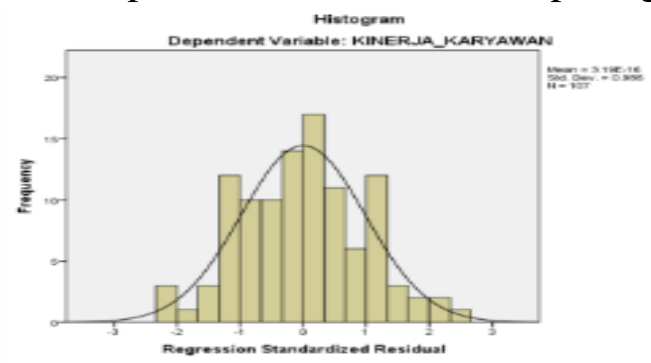

Gambar 4.1 Normalitas Grafik Histogram

Sumber: Pengolahan Data SPSS 22, 2020

Pada gambar 4.1 diatas uji normalitas dengan grafik histogram menghasilkan kurva berbentuk lonceng, sehingga dapat dikatakan data tersebut berdistribusi normal. Pembuktian selanjutnya adalah hasil uji normalitas dengan diagram normal $P-P$ Plot of regression Standarized Residual.

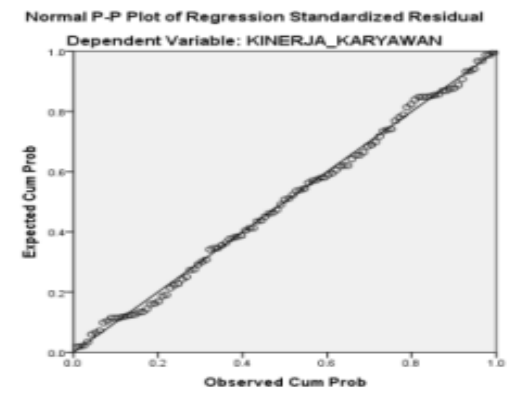

Gambar 4.2 Hasil Uji Normalitas P-P Plot of Regression

Sumber: Pengolahan Data SPSS 22, 2020

Selanjutnya dari hasil uji normalitas dengan analisis one-sample Kolmogorov - smirnov test. Pada uji one-sample Kolmogorov - smirnov test ini data dikatakan berdistribusi normal jika menghasilkan nilai signifikansi (2-tailed $)>$ dari pada nilai alpha 0,050 . Hasil uji analisis sebagai berikut:

Tabel 4.13 One-Sample Kolmogorov-Smirnov Test

\begin{tabular}{|l|l|l|}
\hline \multicolumn{2}{|l|}{} & Standardized Residual \\
\hline N & Mean & 107 \\
\hline & Std. Deviation & .0000000 \\
\hline Most Extreme Differences & Absolute & .98574749 \\
\hline & Positive & .040 \\
\cline { 2 - 3 } & Negative & .040 \\
\hline Test Statistic & .039 \\
\hline Asymp. Sig. (2-tailed) & .040 \\
\hline
\end{tabular}

Sumber: Pengolahan Data SPSS 22, 2020

Pada tabel 4.13 yang ada diatas telah diperoleh nilai signifikasi 0,200 >0,05 nilai alpha, sehingga bisa diambil kesimpulan bahwa data memiliki distribusi yang normal. Hasil Uji Multikolinearitas 
Tabel 4.14 Hasil Uji Multikolinearitas Coefficients ${ }^{\mathrm{a}}$

\begin{tabular}{|l|l|c|c|}
\hline \multicolumn{2}{|c|}{ Model } & \multicolumn{2}{c|}{ Collinearity Statistics } \\
\cline { 2 - 4 } \multicolumn{2}{|c|}{1} & Tolerance & VIF \\
\hline \multirow{3}{*}{1} & Disiplin_Kerja & .417 & 2.400 \\
\cline { 2 - 4 } & Pengalaman_Kerja & .601 & 1.665 \\
\cline { 2 - 4 } & Budaya_Organisasi & .501 & 1.994 \\
\hline \multicolumn{2}{|l|}{ a. Dependent Variable: Kinerja_Karyawan }
\end{tabular}

Sumber: Pengolahan Data SPSS 22, 2020

Pada tabel 4.14 diatas dapat dilihat hasil uji multikolinearitas dari ketiga variabel independen lebih dari 0,1 dan VIF kurang dari 10, sehingga bisa diambil kesimpulan bahwa dalam model regresi tidak ada masalah dengan multikolinearitas.

Hasil Uji Heteroskedastisitas

Tabel 4.15 Hasil Uji Heterokedastisitas Coefficients ${ }^{\mathbf{a}}$

\begin{tabular}{|c|c|c|c|c|c|}
\hline \multirow[t]{2}{*}{ Model } & \multicolumn{2}{|c|}{$\begin{array}{l}\text { Unstandardized } \\
\text { Coefficients }\end{array}$} & \multirow{2}{*}{$\begin{array}{c}\text { Standardized } \\
\text { Coefficients } \\
\text { Beta }\end{array}$} & \multirow[t]{2}{*}{$\mathbf{t}$} & \multirow[t]{2}{*}{ Sig. } \\
\hline & B & Std. Error & & & \\
\hline (Constant) & $6.132 \mathrm{E}-16$ & 2.288 & & .000 & 1.000 \\
\hline Disiplin_Kerja & .000 & .087 & .000 & .000 & 1.000 \\
\hline Pengalaman_Kerja & .000 & .074 & .000 & .000 & 1.000 \\
\hline Budaya_Organisasi & .000 & .087 & .000 & .000 & 1.000 \\
\hline
\end{tabular}

Sumber: Pengolahan Data SPSS 22, 2020

Sebuah model dibilang tidak terdapat gejala heteroskedastisitas jika nilai probabilitas dan signifikansi > 0,05. Pada tabel 4.15 diatas dapat dilihat bahwa nilai probabilitas dan signifikansinya untuk setiap variabel 1,000. Dan dapat disimpulkan bahwa penelitian ini tidak memiliki gejala heteroskedastisitas.

Hasil Uji Analisis Regresi Linear Berganda

Tabel 4.16 Hasil Uji Analisis Regresi Linear Berganda

\begin{tabular}{|c|c|c|c|c|c|}
\hline \multirow[t]{2}{*}{ Model } & \multicolumn{2}{|c|}{$\begin{array}{l}\text { Unstandardized } \\
\text { Coefficients }\end{array}$} & \multirow{2}{*}{$\begin{array}{c}\begin{array}{c}\text { Standardized } \\
\text { Coefficients }\end{array} \\
\text { Beta } \\
\end{array}$} & \multirow[t]{2}{*}{$\mathbf{t}$} & \multirow[t]{2}{*}{ Sig. } \\
\hline & B & Std. Error & & & \\
\hline (Constant) & 1.063 & 2.288 & & .464 & .643 \\
\hline Disiplin_Kerja & .330 & .087 & .343 & 3.803 & .000 \\
\hline 'Pengalaman_Kerja & .194 & .074 & .198 & 2.633 & .010 \\
\hline Budaya_Organisasi & .409 & .087 & .385 & 4.688 & .000 \\
\hline
\end{tabular}

Sumber: Pengolahan Data SPSS 22, 2020

Dari tabel 4.16 diatas bisa disimpulkan bahwa catatan persamaan regresi linear berganda yang dibuat sebagai berikut :

$\mathrm{Y}=1,063+0,330(\mathrm{X} 1)+0,194(\mathrm{X} 2)+0,409(\mathrm{X} 3)$

Maka dari persamaan diatas dapat dibuat keputusan sebagai berikut : 
1. Nilai konstanta 1,063 yang artinya bahwa variabel independen disiplin kerja (X1), pengalaman kerja (X2) dan budaya organisasi (X3) adalah nol (0) dan variabel dependen kinerja karyawan (Y) adalah konstan atau sama dengan senilai 1,063.

2. Pada variabel disiplin kerja (X1) memilki koefisien regresi 0,330 yang berarti bahwa variabel independen lainnya $(X)$ tetap atau tidak berubah maka tiap 1 peningkatan poin, variabel disiplin kerja akan meningkatkan kinerja karyawan yang meningkat sebesar 0,330. Koefisien positif, yang artinya variabel disiplin kerja (X1) memilki pengaruh terhadap kinerja karyawan (Y) positif. Dan hasil uji t menerima tingkat signifikan 0,000. Lalu Ho ditolak dan Ha diterima yang berarti memilki pengaruh yang positif. Dan disiplin kerja memilki dampak yang positif dan signifikan pada kinerja karyawan.

3. Pada variabel pengalaman kerja (X2) memilki koefisien regresi 0,194 yang berarti bahwa variabel independen lainnya $(\mathrm{X})$ tetap atau tidak berubah maka tiap 1 peningkatan poin, variabel pengalaman kerja akan meningkatkan kinerja karyawan yang meningkat sebesar 0,194. Koefisien positif, yang artinya variabel pengalaman kerja (X2) memilki pengaruh terhadap kinerja karyawan (Y) positif. Dan hasil uji t menerima tingkat signifikan 0,000. Lalu Ho ditolak dan Ha diterima yang berarti memilki pengaruh yang positif. Dan pengalaman kerja memiliki dampak yang positif dan signifikan pada kinerja karyawan.

4. Pada variabel budaya organisasi (X3) memiliki koefisien regresi 0,409 yang berarti bahwa variabel independen lainnya $(\mathrm{X})$ tetap atau tidak berubah maka tiap 1 peningkatan poin, variabel budaya organisasi akan meningkatkan kinerja karyawan yang meningkat sebesar 0,409. Koefisien positif, yang artinya variabel budaya organisasi (X3) memilki pengaruh terhadap kinerja karyawan (Y) positif. Dan hasil uji t menerima tingkat signifikan 0,000. Lalu Ho ditolak dan Ha diterima yang berarti memiilki pengaruh yang positif. Dan budaya organisasi memiliki dampak yang positif dan signifikan pada kinerja karyawan.

\section{Hasil Uji Determinasi}

Uji determinasi guna mengetahui suatu gambaran seberapa banyak persentase pengaruh variabel independen secara simultan terhadap variabel kinerja karyawan.

Tabel 4.17 Hasil Uji Determinasi Model Summary ${ }^{\mathrm{b}}$

\begin{tabular}{|c|c|c|c|c|}
\hline Model & $\mathbf{R}$ & R Square & Adjusted R Square & $\begin{array}{c}\text { Std. Error of the } \\
\text { Estimate }\end{array}$ \\
\hline 1 & $.807^{\mathrm{a}}$ & .652 & .641 & 2.093 \\
\hline
\end{tabular}

a. Predictors: (Constant), Budaya_Organisasi, Pengalaman_Kerja, Disiplin_Kerja

b. Dependent Variable: Kinerja_Karyawan

\section{Sumber: Pengolahan Data SPSS 22, 2020}

Pada tabel 4.17 diatas, dilihat bahwa nilai R square sebesar 0,652 dimana variabel disiplin kerja, pengalaman kerja dan budaya organisasi secara bersamaan berpengaruh terhadap kinerja karyawan sebesar $65,2 \%$. Sedangkan sisanya 34,8\% yang dipengaruhi oleh faktor lain yang mempengaruhi kinerja karyawan yang tidak dimasukkan kedalam penelitian ini. Dan hipotesis tentang disiplin kerja, pengalaman kerja, dan budaya organisasi secara simultan berpengaruh positif dan signifikan terhadap kinerja karyawan dapat diterima.

\section{Hasil Uji T (Parsial)}

Tabel 4.18 Hasil Uji t 


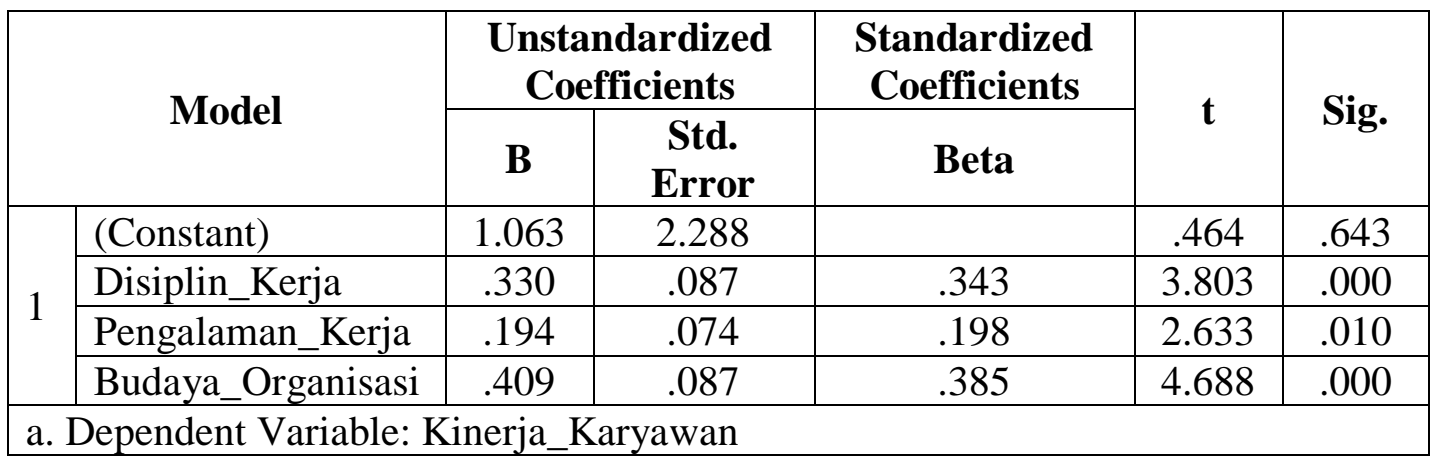

Sumber: Pengolahan Data SPSS 22, 2020

Dari tabel 4.18 hasil uji t diatas maka ditarik kesimpulan untuk hipotesis yang telah dibuat, sebagai berikut:

Nilai thitung yang diperoleh pada variabel disiplin kerja adalah 3,803 > 1,98326 pada nilai $t_{\text {tabel }}$ dan signifikansi pada variabel disiplin kerja $0,000<0,05$ nilai alpha, jadi hipotesis pertama pada penelitian ini dapat diterima. Sehingga disiplin kerja berpengaruh positif dan signifikan terhadap kinerja karyawan pada PT Kumala Indonesia Shipyard.

Nilai thitung yang diperoleh pada variabel pengalaman kerja adalah 2,633 $>1,98326$ pada nilai $t_{\text {tabel }}$ dan signifikansi pada variabel pengalaman kerja $0,010<0,05$ nilai alpha, jadi hipotesis kedua pada penelitian ini dapat diterima. Sehingga pengalaman kerja berpengaruh positif dan signifikan terhadap kinerja karyawan pada PT Kumala Indonesia Shipyard.

Nilai thitung yang diperoleh pada variabel budaya organisasi adalah 4,688 $>1,98326$ pada nilai $t_{\text {tabel }}$ dan signifikansi pada variabel budaya organisasi $0,000<0,05$ nilai alpha, jadi hipotesis ketiga pada penelitian ini dapat diterima. Sehingga budaya organisasi berpengaruh positif dan signifikan terhadap kinerja karyawan pada PT Kumala Indonesia Shipyard.

\section{Hasil Uji F (Simultan)}

Tabel 4.19 Model Summary ${ }^{\mathrm{b}}$ Uji F

\begin{tabular}{|c|c|c|c|c|}
\hline Model & R & R Square & Adjusted R Square & $\begin{array}{c}\text { Std. Error of the } \\
\text { Estimate }\end{array}$ \\
\hline 1 & $.760^{\text {a }}$ & .577 & .569 & 2.294 \\
\hline \multicolumn{2}{l}{ a. Predictors: (Constant), Pengalaman_Kerja, Disiplin_Kerja } \\
\hline
\end{tabular}

Sumber: Pengolahan Data SPSS 22, 2020

Tabel 4.20 Hasil Uji F

\begin{tabular}{|l|c|c|c|c|c|c|}
\hline \multicolumn{2}{|c|}{ Model } & Sum of Squares & df & $\begin{array}{c}\text { Mean } \\
\text { Square }\end{array}$ & F & Sig. \\
\hline \multirow{3}{*}{1} & Regression & 747.012 & 2 & 373.506 & 70.986 & $.000^{\mathrm{b}}$ \\
\cline { 2 - 7 } & Residual & 547.212 & 104 & 5.262 & & \\
\cline { 2 - 6 } & \multicolumn{2}{|l}{ Total } & 1294.224 & 106 & & \\
\hline \multicolumn{2}{|l}{ a. Predictors: (Constant), Pengalaman_Kerja, Disiplin_Kerja } \\
\multicolumn{2}{l}{ b. Dependent Variable: Kinerja_Karyawan }
\end{tabular}

Sumber: Pengolahan Data SPSS 22, 2020

Hasil dari hipotesis keempat (H4) argument nilai $\mathrm{F}_{\text {hitung }} 70.986>\mathrm{F}_{\text {tabel }} 2.69$, dan sig $<$ alpha dengan nilai $0,000<0,050$. Dari perbandingan diatas bisa disimpulkan hipotesis 
keempat (H4) diterima yang berarti variabel disiplin kerja dan pengalaman kerja berpengaruh signifikan terhadap kinerja karyawan pada PT Kumala Indonesia Shipyard.

Tabel 4.21 Model Summary ${ }^{\mathrm{b}}$ Uji F

\begin{tabular}{|c|c|c|c|c|}
\hline Model & $\mathbf{R}$ & R Square & $\begin{array}{c}\text { Adjusted R } \\
\text { Square }\end{array}$ & $\begin{array}{c}\text { Std. Error of the } \\
\text { Estimate }\end{array}$ \\
\hline 1 & $.776^{\mathrm{a}}$ & .603 & .595 & 2.224 \\
\hline
\end{tabular}

Sumber: Pengolahan Data SPSS 22, 2020

Tabel 4.22 Anova Uji F

\begin{tabular}{|l|l|l|c|l|c|c|}
\hline \multicolumn{2}{|c|}{ Model } & Sum of Squares & df & $\begin{array}{c}\text { Mean } \\
\text { Square }\end{array}$ & F & Sig. \\
\hline \multirow{3}{*}{1} & Regression & 779.892 & 2 & 389.946 & 78.849 & $.000^{\mathrm{b}}$ \\
\cline { 2 - 7 } & Residual & 514.332 & 104 & 4.946 & & \\
\cline { 2 - 6 } & Total & 1294.224 & 106 & & & \\
\hline \multicolumn{2}{|l|}{ a. Predictors: (Constant), Budaya_Organisasi, Pengalaman_Kerja } \\
\hline
\end{tabular}

Sumber: Pengolahan Data SPSS 22, 2020

Hasil dari hipotesis kelima (H5) argument nilai Fhitung $78.849>$ Ftabel 2.69, dan sig < alpha dengan nilai $0,000<0,050$. Dari perbandingan diatas bisa disimpulkan hipotesis kelima (H5) diterima yang berarti variabel pengalaman kerja dan budaya organisasi berpengaruh signifikan terhadap kinerja karyawan pada PT Kumala Indonesia Shipyard.

\section{SIMPULAN}

Maka dapat ditarik kesimpulan sebagai berikut :

1. Variabel disiplin kerja berpengaruh secara parsial positif dan signifikan terhadap kinerja karyawan pada PT Kumala Indonesia Shipyard. Maka yang berarti bahwa disiplin kerja harus dilakukan dengan baik agar dapat meningkatkan kinerja karyawan.

2. Variabel pengalaman kerja berpengaruh secara parsial positif dan signifikan terhadap kinerja karyawan. Maka artinya bahwa pengalaman kerja yang cukup lama akan mempengaruhi kinerja karyawan pada PT Kumala Indonesia Shipyard.

3. Variabel budaya organisasi juga berpengaruh secara parsial positif dan signifikan terhadap kinerja karyawan pada PT Kumala Indonesia Shipyard. Maka artinya bahwa budaya organisasi yang baik akan meningkatkan kinerja karyawan.

4. Variabel disiplin kerja dan pengalaman kerja berpengaruh secara simultan positif dan signifikan terhadap kinerja karyawan pada PT Kumala Indonesia Shipyard. Disiplin kerja yang baik akan menghasilkan kinerja yang baik pula begitu juga pada pengalaman kerja yang dimilki seorang pengalaman yang cukup lama akan berpengaruh terhadap hasil kinerja yang dihasilkan.

5. Variabel pengalaman kerja dan budaya organisasi berpengaruh secara simultan positif dan signifikan terhadap kinerja karyawan pada PT Kumala Indonesia Shipyard. Pengalaman kerja serta budaya organisasi yang dikelola dengan baik akan menghasilkan kinerja yang sesuai prosedur perusahaan.

\section{DAFTAR PUSTAKA}


Acel, N., \& Abrian, Y. (2019). Pengaruh disiplin kerja terhadap kinerja karyawan di the premier basko hotel padang. 11(1).

Candra, V., Dharma, E., \& Sherly. (2020). Contribution of Discipline to Forming Employee Perfomance at the Community Health Center ( Puskesmas ) of Raya Pematangsiantar City. 3(2), 366- 372.

Darmasaputra, i komang alan, \& Sudibya, i gede adnyana. (2019). Pengaruh Kepemimpinan Transaksional, Budaya Organisasi dan Komunikasi Terhadap Kinerja Karyawan. 8(9), 5847-5866.

Effendi, M., \& Yogie, F. (2019). Pengaruh Motivasi dan Disiplin Kerja Terhadap Kinerja Karyawan. 1, 88-98.

Muis, M. R., Jufrizen, J., \& Fahmi, M. (2018). Pengaruh Budaya Organisasi Dan Komitmen Organisasi Terhadap Kinerja Karyawan. Jesya (Jurnal Ekonomi \& Ekonomi Syariah), 1(1), 9-25. https://doi.org/10.36778/jesya.v1i1. 7

Prahasti, S., \& Wahyono. (2018). Pengaruh Gaya Kepemimpinan, Budaya Organisasi dan Lingkungan Kerja Terhadap Kinerja Pegawai Dengan Kepuasan Kerja Sebagai Mediator. 2(1), 18-23.

Prasetyo, E. T., \& Marlina, P. (2019). Pengaruh Disiplin Kerja dan Kepuasan Kerja Terhadap Kinerja Karyawan. 3(1), 21-30.

Rahmi, N. (2019). Pengaruh Pelatihan Gaya Kepemimpinan dan Disiplin Kerja Terhadap Kinerja Karyawan PT. Perkebunan Nusantara XIV (Persero) Makassar. 2.

Ratnasih, P. (2019). Pengaruh pengalaman kerja dan kepuasan kerja terhadap kinerja guru di podok pesantren. Scientific Journal of Reflection, 2(3), 291-300. https://doi.org/10.5281/zenodo.3269366

Rulianti, E. (2019). Pengaruh Pengalaman Kerja Dan Penempatan Karyawan Terhadap Kinerja Karyawan. Jurnal Manajemen Indonesia, 4(1), 131- 138.

Siagian, M. (2017). Analisis Budaya Organisasi, Disiplin Kerja, Dan Pengembangan Sumber Daya Manusia Terhadap Kinerja Pegawai Dengan Motivasi Kerja Sebagai Variabel Intervening di Kantor Pemerintah Kecamatan Lubuk Baja Batam. 2.

Sofian, E., \& Julkarnain. (2019). Pengaruh Pengalaman Kerja dan semangat Kerja terhadap Kinerja karyawan di PT. Duta Griya Sarana Medan. 4(2), 142-149.

Umar, H. (2014). Metode Penelitian Untuk Skripsi Dan Tesis Bisnis. 